\title{
Degradation of Shielding Performance of Metallic Sheet due to Aperture Configuration and Dimension at $2.4 \mathrm{GHz}$
}

\author{
Adik Susilo Wardoyo ${ }^{\text {a, }}$, Mudrik Alaydrus ${ }^{\text {b }}$ \\ ${ }^{a}$ Department of Electronic Engineering \\ Politeknik Gajah Tunggal \\ Komplek Industri Gajah Tunggal, Jalan Gatot Soebroto, Km.7, Pasir Jaya, Jatiuwung \\ Tangerang, Indonesia \\ ${ }^{b}$ Department of Electrical Engineering \\ Universitas Mercu Buana Jakarta \\ Jalan Meruya Selatan No.1, Joglo, Kembangan, Jakarta Barat \\ Jakarta, Indonesia
}

\begin{abstract}
The increasing demand on wireless connectivity has opened new and modern communication systems. Many wireless systems, for example Wireless Fidelity (Wi-Fi), Bluetooth, ZigBee, share the unlicensed frequency region around 2.4 GHz. Due to intensive application of Wi-Fi systems, there are certain disturbance potentials observed. The Wi-Fi signals cause interference to ZigBee networks which are used for smart grid applications. In this work, the shielding effectiveness of a metallic enclosure with several apertures is studied. Based on analytical expression from the literature, the shielding effectiveness by varying the sheet thickness, number of apertures, and aperture patterns is calculated. Several measurements of Received Signal Strength Indicator (RSSI) are carried out. The measurements are conducted on a shielded room to isolate the measurement from other unknown signal sources.

The calculation and measurement of shielding effectiveness confirmed that more apertures on a shielding sheet will reduce the Shielding Effectiveness (SE). SE for one aperture for the case sheet thickness $0.7 \mathrm{~mm}$ and diameter of $12 \mathrm{~mm}$ reduce from $46.28 \mathrm{~dB}$ to $14.24 \mathrm{~dB}$ for 6 apertures. Bigger aperture diameters will also degrade the SE from $46.28 \mathrm{~dB}$ to $5.27 \mathrm{~dB}$ for aperture diameter $24 \mathrm{~mm}$. The same condition can be concluded for the thickness $1.4 \mathrm{~mm}$ for aperture diameter of $12 \mathrm{~mm}$. However a slightly different measurement results are obtained for the thickness $1.4 \mathrm{~mm}$ and aperture diameter of $24 \mathrm{~mm}$. The thickness plays a significant role to attenuate the wave, so that $\mathrm{SE}$ is bigger than the calculated one.
\end{abstract}

Keywords: Electromagnetic shielding, shielding effectiveness, stainless steel, shielded box method.

\section{INTRODUCTION}

The increasing demand on wireless connectivity has opened new and modern communication systems [1]. Due to the needs on higher capacity, several new frequency regions are used. However many wireless systems use the available frequency regions jointly. Some communications systems, such as Wireless Fidelity (Wi-Fi), Bluetooth, ZigBee, share the unlicensed frequency region around $2.4 \mathrm{GHz}$.

Due to intensive application of Wi-Fi systems, there are certain disturbance potentials observed. In [2], the interference of Wi-Fi signals to ZigBee for smart grid applications is discussed. An improved design guideline is developed to mitigate the $\mathrm{Wi}-\mathrm{Fi}$ interference to enhance the performance of the smart grid system.

In wireless communication, the Received Signal Strength Indicator (RSSI) is often used to indicating the amount of signal received from a wireless communication. Heurtefeux and Valois [3] described

\footnotetext{
* Corresponding Author.

Email: adiksusilo@poltek-gt.ac.id

Received: January 19, 2018 ; Revised: February 28, 2018

Accepted: April 02, 2018 ; Published: August 31, 2018

(C) 2018 PPET - LIPI
}

that the RSSI is an indicator of the signal strength level received by the antenna, the greater the value of RSSI, the greater the signal value received and the closer to the distance. Based on D. Micheli et al. [4], which concluded that experiments carried out in frequency interval of $700 \mathrm{MHz}$ to $5 \mathrm{GHz}$, there are certain variation of RSSI due to different material samples, such as concrete, brick, concrete-marble, and indoor partitions of different thickness. The research indicates that variation of material and material thickness can change the RSSI. In addition, Pavlik, et al. [5] mentioned that there are effects of the brick wall at a frequency of $1.5-9 \mathrm{GHz}$, with a linear increase of the attenuation of the fields with the wall thickness [5]. But in his research, it was only done by the brick and concentrated on the effects of material. Robinson [7] and Wang [11] gave analytical expressions for calculation of the shielding effectiveness, which are the basics of our work.

In this work, we compare the calculated and measured shielding effectiveness of the Stainless Steel 304 to block the Wi-Fi signal (frequency $2.4 \mathrm{GHz}$ ) by varying the steel sheet thickness, and the number of the apertures as well as its diameter. 


\section{THEORY}

\section{A. Electromagnetic Shielding}

Shielding effectiveness is defined as the ratio of the strength of the electromagnetic field in a shielded area to the outside area [6]. Shielding ability is described by electrical Shielding Effectiveness (SE) and Magnetic Shielding Effectiveness (SM) [6]. The electromagnetic interference is essentially a natural interference and an unexpected electromagnetic emission either by radiation or channelling. Metallic materials are the best materials for electromagnetic shielding; however they are expensive and heavy. Sometimes polymeric materials are used as a protective device for light, flexible, and inexpensive electronics, but shielding effectiveness of polymer material is zero [6].

For an infinite conducting sheet, illuminated by a plane wave, SE and SM are equal and depend only on the frequency and on the conductivity, permeability, and thickness of the sheet. But for a shielding box, the SE and SM values can be different, depending on the position of the shield. It can be further explained that the penetration of the wave will be focused through the existing aperture or gap of the existing aperture, not through the enclosure wall [7].

Shielding effectiveness is the ratio of the incident field and the transmitted field [8]. For the sake of measurements, the shielding effectiveness of a material is defined as the ratio of field strength by absence and by presence of the material measured behind the material [9]. Shielding effectiveness (SE) is influenced by the number and dimension of the apertures, through them the electromagnetic waves penetrate.

\section{B. Measurement of Electromagnetic Shielding Effectiveness}

Several measurements methods are proposed in [10] which are open field or free space method, shielded box method, and shielded room method, which are described as follows.

\section{1) Open Field or Free Space Method}

This method can be applied to evaluate shielding effectiveness in ready-made electronic circuits. This method is used to measure radiation emissions coming out from finished products. The measurement with this method does not measure the performance of specific materials. The test method is depicted in Figure 1 [8].

\section{2) Shielded Box Method}

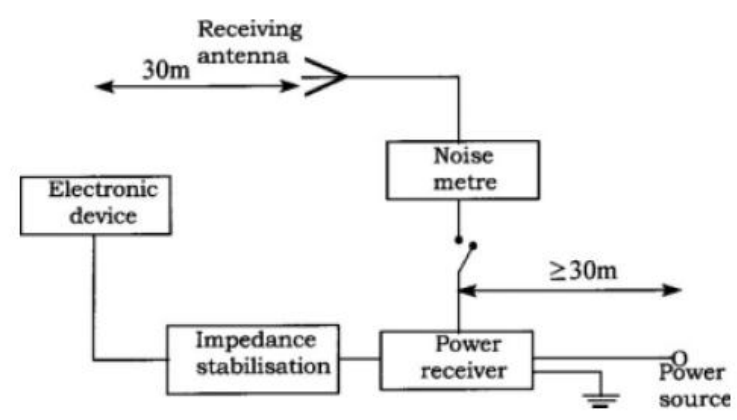

Figure 1. Open Field Method [8]

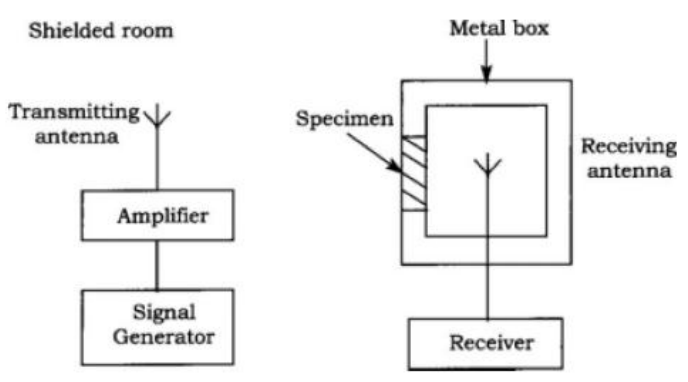

Figure 2. Shielded Box Method [8]

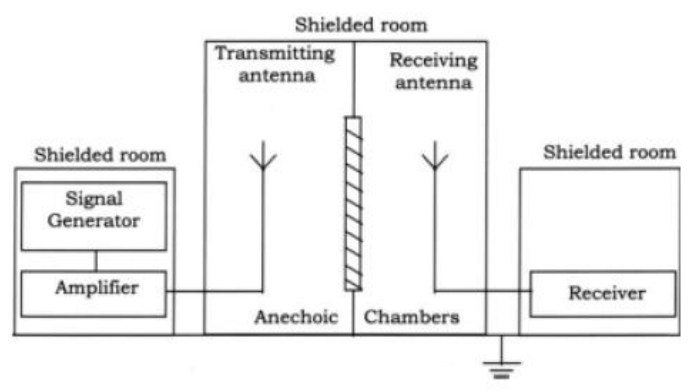

Figure 3. Shielded Room Measurement Method [8]

This method is used to measure and compare specimens of different materials characteristic. The method consists of a metal box with a port to place the sample to be measured and dilated to the receiving antenna. The transmitting antenna is placed out of the box, and the intensity of the received signal inside the box is recorded and compared if the port is sampled and there is no illustrative sample of this method as shown in Figure 2 [8].

\section{3) Shielded Room Method}

The principle of the shielded room method, as given in Figure 3, is almost the same as the closed box method, but the measurement component, the generator, the transmitting antenna receiver antenna is isolated and split in different spaces. This method was created to minimize external interference [8].

\section{Shielding Effectiveness Calculation}

For calculating the shielding effectiveness of an enclosure box with an aperture, a metallic box with a dimension of $a \times b \times d$ (Figure $4 a$ ) is used. A probe for measuring penetrating waves will be located at a distance of $p$ behind the aperture. The dimension and position of the aperture is shown in Figure 4b).

For evaluating the penetrating waves, an equivalent circuit is modelled in Figure 5. It shows the equivalent circuit by adding a parallel stub circuit to model the aperture on the front of the enclosure. $Z_{O S}$ is the characteristic impedance modelling the aperture, which can be determined with (1) [11].

$Z_{o s}=120 \pi^{2}\left[\ln \left(2 \frac{\left.1+\sqrt[4]{1-\left(w_{e} / b\right.}\right)^{2}}{\left.1-\sqrt[4]{1-\left(w_{e} / b\right.}\right)^{2}}\right)\right]^{-1}$

where $w_{\mathrm{e}}$ the effective width of the aperture is defined in (2), $t$ is the thickness of the metallic sheet and $w$ is the width of the aperture. For circular aperture, the 
formulation used is (3). $d$ is defined as the diameter value of the circular aperture.

$$
\begin{gathered}
w_{e}=w-\frac{5 t}{4 \pi}\left(1+\ln \left(\frac{4 \pi w}{t}\right)\right) \\
l=w=\frac{\sqrt{\pi}}{2} d
\end{gathered}
$$

The value of the impedance of the apertures is transformed from the short circuit with the distance from the aperture reaches the distance of $l / 2$ where the value of $l$ is the length of the aperture, so that the formula will be (4) [11]. $C_{m}$ is calculated by using (5) [12]. If there are several apertures of the same dimension $(n)$, then to find the impedance value, (6) can be used [11].

$$
\begin{gathered}
Z_{a p}=\frac{1}{2} C_{m} Z_{0 s} \frac{Z_{l}+j Z_{o s} \tan \left(\frac{k_{0} l}{2}\right)}{Z_{o s}+j Z_{l} \tan \left(\frac{k_{0} l}{2}\right)} \\
\frac{C_{m}=}{\int_{x_{0}}^{x_{0}-1} \int_{y_{0}}^{y_{0}+w} \cos \left(\frac{n \pi y}{b}\right) \cos \left(\frac{n\left(y-y_{0}\right) \pi}{w}\right) \sin \left(\frac{n m x}{a}\right) \cos \left(\frac{\pi\left(x-x_{0}\right) \pi}{l}\right) d x d y} \\
x y \\
Z_{a p}=n Z_{a p}
\end{gathered}
$$

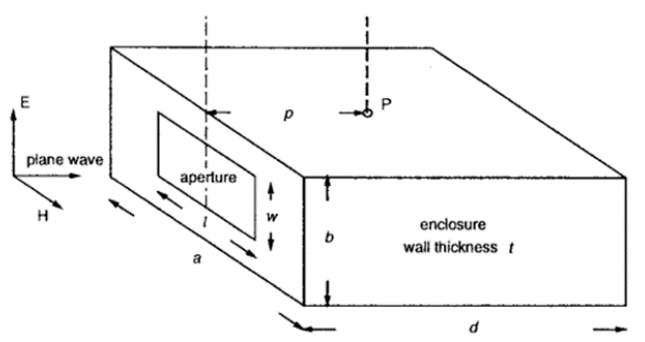

(a)

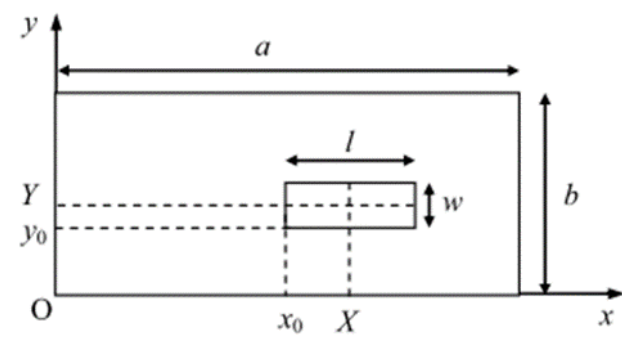

(b)

Figure 4. (a) Enclosure Box with Rectangular Aperture, (b) Position and Dimension of the Aperture [11]

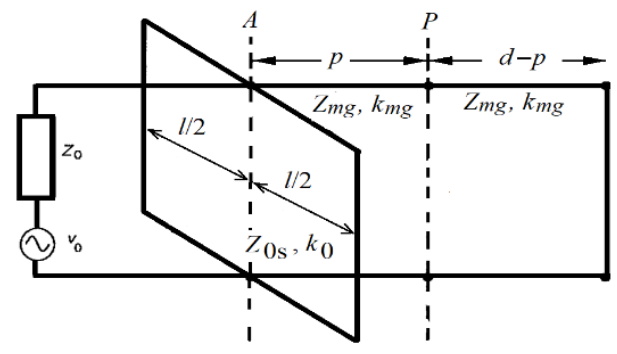

Figure 5. Equivalent Circuit of the Enclosure Box [11]
For a perfect conducting sheet the value of $\mathrm{Z}_{1}$ becomes $0 \mathrm{ohms}$, where as for other materials the value of $Z_{1}$ can be calculated by (7). The values of $\mu_{1}$ and $\sigma_{1}$ represent the magnetic permeability and conductivity of enclosure material respectively [12].

$$
Z_{l}=(1+j) \sqrt{\frac{\pi f \mu_{1}}{\sigma_{1}}}
$$

By using the Thevenin theory combined with $\mathrm{Z}_{0}, v_{0}$, and $\mathrm{Z}_{\mathrm{ap}}$, the value $v_{1}$ is determined by (8) [10], and the value of the source impedance expressed as (9) - (11) [11].

$$
\begin{gathered}
v_{1}=\frac{v_{0} Z_{a p}}{Z_{0}+Z_{a p}} \\
Z_{1}=\frac{Z_{0} Z_{a p}}{\left(Z_{0}+Z_{a p}\right)} \\
V_{2}=\frac{V_{1}}{\cos \left(k_{m g} p\right)+j\left(\frac{Z}{Z}_{m g}\right) \sin \left(K_{m g} p\right)} \\
Z_{2}=Z_{m g} \frac{Z_{1}+j Z_{m g} \tan \left(K_{m g} p\right)}{Z_{m g}+j Z_{1} \tan \left(K_{m g} p\right)}
\end{gathered}
$$

The impedance characteristics of the waveguide in $\mathrm{TE}_{\mathrm{mn}}$ mode and the constant propagation are represented as follows (12) - (13) [11].

$$
\begin{aligned}
& Z_{m g}=\frac{Z_{0}}{\sqrt{1-\left(\frac{m \lambda}{2 a}\right)^{2}-\left(\frac{n \lambda}{2 b}\right)^{2}}} \\
& K_{m g}=\frac{k_{0}}{\sqrt{1-\left(\frac{m \lambda}{2 a}\right)^{2}-\left(\frac{n \lambda}{2 b}\right)^{2}}}
\end{aligned}
$$

where the value of $\mathrm{k}_{0}$ is obtained by $2 \pi / \lambda$.

The transformation of the equivalent impedance from the enclosure surface to $P$, gives the value of $Z_{3}$, obtained from [11], so that the voltage value at $P$ becomes (15). The value of SE can be calculated by (16) with $V_{\mathrm{p}}=V_{0} / 2$ and $V_{\text {ptotal }}=V_{\mathrm{pm}}$.

$$
\begin{gathered}
Z_{3}=Z_{m g} \frac{Z_{l}+j Z_{m g}\left[k_{m g}(d-p)\right.}{Z_{m g}+j Z_{l}\left[k_{m g}(d-p)\right.} \\
V_{p m}=\frac{V_{2} Z_{3}}{Z_{2}+Z_{3}} \\
S E=|20 \log | V_{\text {ptotal }} / V_{p}||
\end{gathered}
$$

\section{Stainless Steel 304 Properties}

Stainless steel is a great material for use in a variety of applications, as it is resistant to corrosion and is easily formed. Stainless Steel type 304 is a variation of 18-8 grade base material, with less chromium and carbon values. The physic properties of the Stainless Steel 304 material is given in Table 1. 
TABLE 1

PHYSIC PROPERTIES OF STAINLESS STEEL 304 [13]

\begin{tabular}{|c|c|}
\hline Density, lbs/in3 (g/cm3) & $0.29(8.03)$ \\
\hline $\begin{array}{l}\text { Electrical resistivity, u } \Omega \text {-in.(u } \Omega-\mathrm{cm}) \\
680 \mathrm{~F}(200 \mathrm{C}) \\
12000 \mathrm{~F}(6590 \mathrm{C})\end{array}$ & $\begin{array}{l}28.4(72) \\
45.8(116) \\
\end{array}$ \\
\hline \multicolumn{2}{|c|}{ Thermal conductivity, BTU/hr./ft./0F (W/m/K) } \\
\hline $\begin{array}{l}2120 \mathrm{~F}(1000 \mathrm{C}) \\
9320 \mathrm{~F}(5000 \mathrm{C})\end{array}$ & $\begin{array}{l}9.1(16.2) \\
12.4(21.4)\end{array}$ \\
\hline \multicolumn{2}{|c|}{ Mean coefficient of thermal expansion, in./in./0F9um/m/K) } \\
\hline $\begin{array}{l}\text { 32-2120F }(0-1000 C) \\
32-6000 F(0-3150 C) \\
32-10000 F(0-5380 C) \\
32-12000 F(0-6490 C)\end{array}$ & $\begin{array}{l}9.4 \times 10-6(16.9) \\
9.9 \times 10-6(17.3) \\
10.2 \times 10-6(18.4) \\
10.4 \times 10-6(18.7)\end{array}$ \\
\hline \multicolumn{2}{|l|}{ Modulus of elasticity, ksi. (Mpa) } \\
\hline In tension & $28.0 \times 103(193 \times 103)$ \\
\hline In torsion & $11.2 \times 103(78 \times 103)$ \\
\hline $\begin{array}{l}\text { Magnetic permeability annealed } \\
\text { (H/m) at } 200 \text { Oerstedts) }\end{array}$ & $1.02 \max$ \\
\hline $\begin{array}{l}\text { Specific heat, BTU/lbs./0F(kK/kg/K) } \\
\text { 32-2120F (0-1000C) }\end{array}$ & $0.12(0.50)$ \\
\hline Melting range, $0 \mathrm{~F}(0 \mathrm{C})$ & $\begin{array}{l}550-2650 \\
(1399-1454)\end{array}$ \\
\hline
\end{tabular}

- Permeability max: $1.02 \mathrm{H} / \mathrm{m}$ [13]

- Conductivity: $1.45 \times 10^{6} \mathrm{~S} / \mathrm{m}$ [14]

- Voltage value of source current $-30 \mathrm{~dB}$ at impedance $50 \Omega=0.00707$ volt [15]

- Electric Mode Transfer Mode selected on $\mathrm{TE}_{11}$ [16]

\section{RESEARCH METHOD}

In this work, we use the shielded room method to do the measurement of the penetrating waves. This method is chosen because by using the Faraday cage, the external interference can be avoided due to available unidentified Wi-Fi signals. The measurement design used in this work is depicted in Figure 6.

The measurement setup consist of two Faraday cages separated by a rectangular waveguide. The transmitter is located in one Faraday cage, whereas the receiver is in other Faraday cage. In the waveguiding structure, the sample under test (stainless steel sheet) is located.

In this study, the experiment was done by measuring the value of RSSI of the received signal power from the access point. The measurement data is acquired by using Acrylic Wi-Fi Professional software. In this work, we make variations of stainless steel thickness, we use stainless steel with thickness $0.7 \mathrm{~mm}$ and $1.4 \mathrm{~mm}$. The dimension of plate are $110 \mathrm{~mm} \times 110 \mathrm{~mm}$.

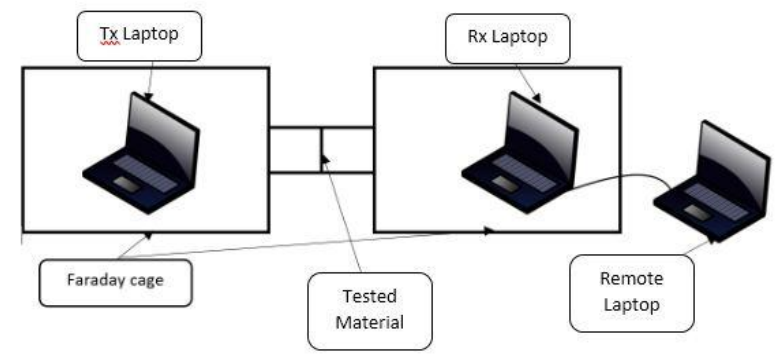

Figure 6. Measurement Design

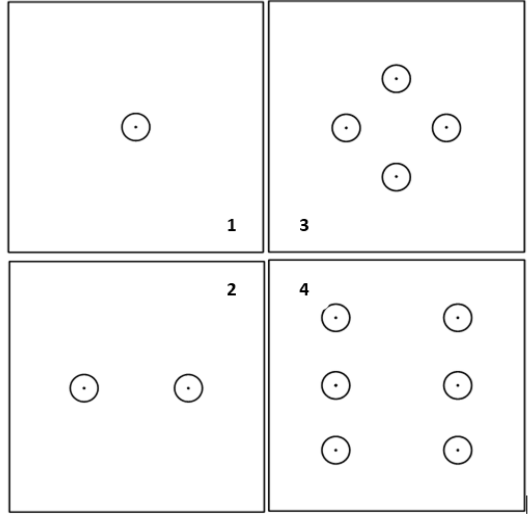

Figure 7. Aperture Pattern on the Stainless Steel with Number of Apertures 1, 2, 4, And 6

The pattern on the apertures varied in size and shape, the sizes used in the study were $12 \mathrm{~mm}$ and 24 $\mathrm{mm}$. The aperture patterns used in this study are shown in Figure 7. The data is captured for 10 seconds, then the experiment is done 5 times. The result of capturing for 10 seconds is seen every second and inserted into the table. Later, the data is averaged and the average results are used as data to compare between calculation and measurement.

\section{RESULT}

\section{A. Calculation Result}

Using the equations given in section IIC and the following geometrical and material parameters, the shielding effectiveness of stainless steel sheet are calculated below.

- $\quad \mathrm{d}=$ according to the diameter of the aperture being tried: $12 \mathrm{~mm} \& 24 \mathrm{~mm}$

- $\quad \mathrm{t}=$ according to the tested thickness of the sample: $0.7 \mathrm{~mm} \& 1.4 \mathrm{~mm}$

- $\quad \mathrm{a}=0.3 \mathrm{~m}, \mathrm{~b}=0.2 \mathrm{~m}, \mathrm{t}=0.007 \mathrm{~m}$

- $\quad p=0.4 \mathrm{~m}, \mathrm{~d}=0.3 \mathrm{~m}$

- The waveguide mode $\mathrm{m}=1, \mathrm{n}=1$

- $\quad x=0.15 \mathrm{~m}$ and $\mathrm{y}=0.1 \mathrm{~m}$

- $\quad$ The free space impedance $\mathrm{Z}_{0}=377 \Omega$

- $\mathrm{V}_{0}=0.00707$ volts

- The frequency $\mathrm{f}=2.4 \times 10^{9} \mathrm{~Hz}$, and $\lambda=0.125$ $\mathrm{m}$

- $\quad$ mag. Permeability $\left(\mathrm{u}_{1}\right)=1.02 \mathrm{H} / \mathrm{m}$

- Conductivity $\left(\sigma_{1}\right)=1.45 \times 10^{9} \mathrm{~S} / \mathrm{m}$

Table 2 and 3 show the calculated SE for $0.7 \mathrm{~mm}$ and $1.4 \mathrm{~mm}$ sheet thickness respectively. As we can see in table 2, due to increasing of the apertures diameter, the SE decreases significantly, the waves penetrate more. As example, for $\mathrm{t}=24 \mathrm{~mm}$ and 2 apertures, we get $\mathrm{SE}$ around $3 \mathrm{~dB}$, which means, around a half of the waves reach the receiver. The values of calculated SE for the thickness $\mathrm{t}=1.4 \mathrm{~mm}$ (table 3 ) are almost the same, as can be seen for $t=0.7 \mathrm{~mm}$. It seems that the thickness of the sheet does not play a significant role. 
TABLE 2

CALCULATION OF SE WITH SAMPLE THICKNESS T $=0.7$ MM AND APERTURE DIAMETER D OF 12 MM AND 24 MM

\begin{tabular}{|l|l|l|}
\hline Number & SE $(\mathbf{d B}), \mathbf{d}=\mathbf{1 2} \mathbf{~ m m}$ & SE $(\mathbf{d B}), \mathbf{d = 2 4} \mathbf{~ m m}$ \\
\hline 1 & 46.27 & 5.26 \\
\hline 2 & 32.83 & 3.13 \\
\hline 4 & 20.39 & 2.55 \\
\hline 6 & 14.24 & 2.45 \\
\hline
\end{tabular}

CALCULATION OF SE WITH SAMPLE THICKNESS T = 1.4 MM AND APERTURE DIAMETER 12 MM AND 24 MM

\begin{tabular}{|l|l|l|}
\hline Number & SE $(\mathbf{d B}), \mathbf{d = 1 2} \mathbf{~} \mathbf{m m}$ & $\mathbf{S E}(\mathbf{d B}), \mathbf{d = 2 4} \mathbf{~ m m}$ \\
\hline 1 & 46.28 & 5.25 \\
\hline 2 & 32.83 & 3.13 \\
\hline 4 & 20.40 & 2.55 \\
\hline 6 & 14.24 & 2.45 \\
\hline
\end{tabular}

\section{B. Measurement Results}

Table 4 and 5 give the measurement data for sheet thickness $0.7 \mathrm{~mm}$ and $1.4 \mathrm{~mm}$ respectively. As we can see in Table 2, due to increasing the diameter of the apertures, the SE decreases significantly, the waves penetrate more. The measurement confirms the theoretical results, although here we have slightly bigger SE value than the calculated ones.

However, for a sheet thickness of $1.4 \mathrm{~mm}$, the measurement shows rather different results than calculation, as given in table 5. It seems although the aperture dimension gets bigger, the thickness of the sheet plays a significant role to attenuate the wave during penetration through the apertures.

TABLE 4

MEASUREMENT OF SE WITH SAMPLE THICKNESS T $=0.7$ MM AND APERTURE DIAMETER D OF 12 MM AND 24 MM

\begin{tabular}{|l|l|l|}
\hline Number & SE $(\mathbf{d B}), \mathbf{d}=\mathbf{1 2} \mathbf{~ m m}$ & SE $(\mathbf{d B}), \mathbf{d}=\mathbf{2 4} \mathbf{~ m m}$ \\
\hline 1 & 41.68 & 7.72 \\
\hline 2 & 32.92 & 3.72 \\
\hline 4 & 26.56 & 3.18 \\
\hline 6 & 18.6 & 4 \\
\hline
\end{tabular}

TABLE 5

MEASUREMENT OF SE WITH SAMPLE THICKNESS T $=1.4$ MM AND APERTURE DIAMETER D OF 12 MM AND 24 MM

\begin{tabular}{|l|l|l|}
\hline Number & SE $(\mathbf{d B}), \mathbf{d}=\mathbf{1 2} \mathbf{~ m m}$ & $\mathbf{S E}(\mathbf{d B}), \mathbf{d}=\mathbf{2 4} \mathbf{~ m m}$ \\
\hline 1 & 46.2 & 7.6 \\
\hline 2 & 38.8 & 6.04 \\
\hline 4 & 29.14 & 1.62 \\
\hline 6 & 17.6 & 4.9 \\
\hline
\end{tabular}

\section{Comparison Calculation and Measurement Data}

Figures 8 to 11 showed the graphical comparison between calculation and measurement given in previous section. In general, the measurement confirmed the calculation very well. However for the case of sheet thickness $1.5 \mathrm{~mm}$ and aperture diameter $24 \mathrm{~mm}$, the attenuation of wave through aperture play a significant role to reduce the wave due to the evanescent mode of the wave [16]. Probably, the analytical expression given in [11] must be improved with this wave phenomenon.

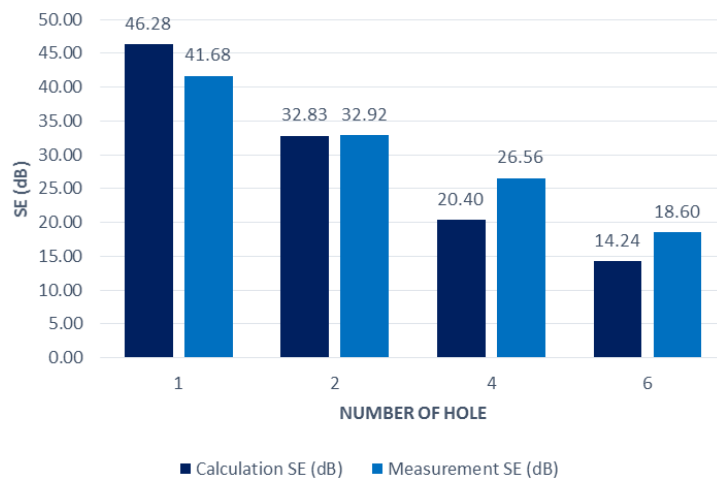

Figure 8. Comparison of calculated and measured SE with $12 \mathrm{~mm}$ aperture diameter and $0.7 \mathrm{~mm}$ thickness

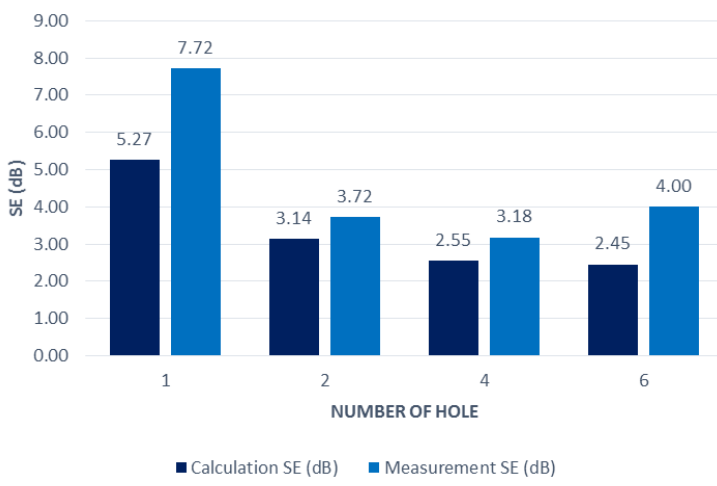

Figure 9. Comparison of calculated and measured SE with $24 \mathrm{~mm}$ aperture diameter and $0.7 \mathrm{~mm}$ thickness

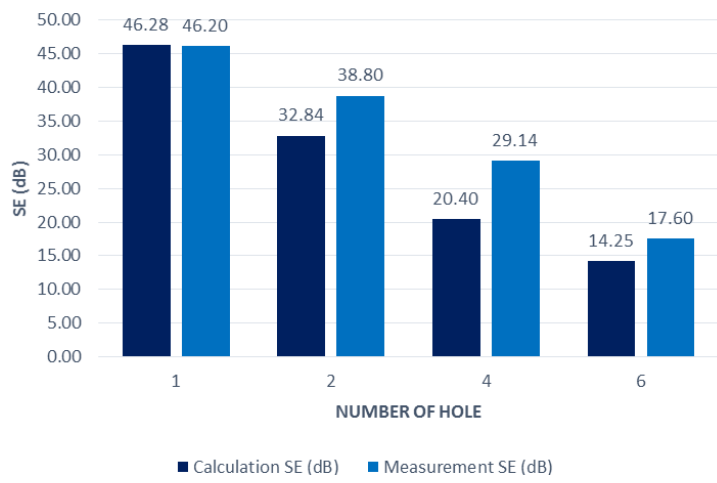

Figure 10. Comparison of calculated and measured SE with $12 \mathrm{~mm}$ aperture diameter and $1.4 \mathrm{~mm}$ thickness 


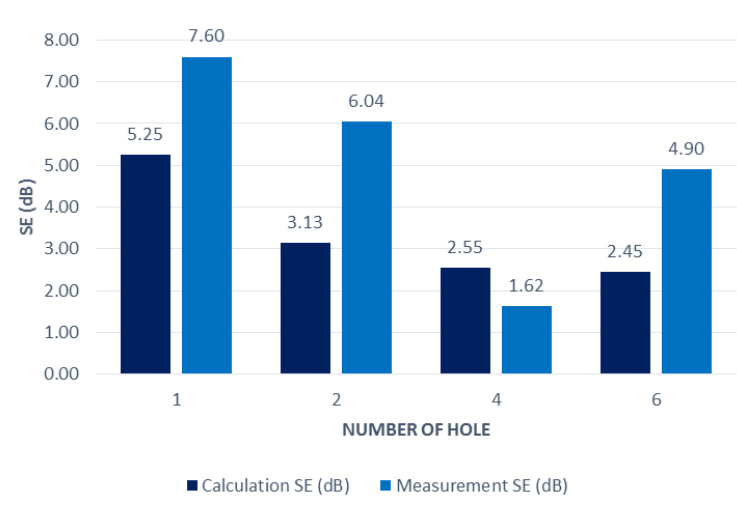

Figure 11. Comparison of calculated and measured SE with $24 \mathrm{~mm}$ aperture diameter and $1.4 \mathrm{~mm}$ thickness

\section{CONCLUSION}

The calculation and measurement of shielding effectiveness (SE) confirmed that more apertures on a shielding sheet will reduce the SE. In the case of 0.7 $\mathrm{mm}$ sheet thickness and $12 \mathrm{~mm}$ diameter, SE reduces from $46.28 \mathrm{~dB}$ for 1 aperture to $14.24 \mathrm{~dB}$ for 6 apertures. Bigger aperture diameters will also degrade the $\mathrm{SE}$ as for $24 \mathrm{~mm}$ diameter aperture, it degrades from $46.28 \mathrm{~dB}$ to $5.27 \mathrm{~dB}$. The same condition can be concluded for the thickness $1.4 \mathrm{~mm}$ for aperture diameter of $12 \mathrm{~mm}$. However a slightly different measurement results are obtained for the thickness 1.4 $\mathrm{mm}$ and aperture diameter of $24 \mathrm{~mm}$. The thickness plays a significant role to attenuate the wave, so that $\mathrm{SE}$ is bigger than the calculated one.

\section{REFERENCES}

[1] A.A. Zavala, Indoor Wireless Communications, Wiley, 2017.

[2] P.Yi, A. Iwayemi, and C. Zhou, "Developing ZigBee deployment guideline under WiFi interference for smart grid applications", IEEE Transaction on Smart Grid, vol. 2, no. 1, pp. 110-120, March 2011.

[3] K. Heurtefeux and F. Valois, "Is RSSI a good choice for localization in wireless sensor network?", in Proc. 2012 26th IEEE International Conference on Advanced Information Networking and Applications, 2012, p. 732 739.

[4] D. Micheli, A. Delfini, F. Santoni, F. Volpini M. Marchetti, "Measurement of electromagnetic field attenuation by building wall in the mobile phone and satellite navigation", IEEE Antennas and Wireless Propagation Letters, vol. 14, 698-702 Dec 2014.

[5] M. Pavlik, D. Medved, and I. Kulcunova, "Measuring of the shielding effectiveness of electromagnetic field of brick wall in the frequency range from $1 \mathrm{GHz}$ to $9 \mathrm{Ghz}$, in Proccedings of the 2014 15th International Scientific Conference of Electric Power Engineering (EPE), May 2014

[6] N. C. Das, D. Khastgir, T. K. Chaki, A. Chakraborty." Electromagnetic Interference Shielding Effectiveness of Carbon Black and Carbon Fiber Filler EVA and NR Based Composites", Elsevier Composites: Part A 31 , vol. 10, pp. 1069-1081, Oct 2000.

[7] M. P. Robinson, T. M. Benson, C. Christopoulos, J. F. Dawson, M.D. Ganley, A. C. Marvin, S. J. Porter, D. W. P. Thomas. "Analytical formulation for the shielding effectiveness of enclosure with apertures", IEEE Transactions on Electromagnetic Compatibility, vol. 40, no. 33, pp 240-248, Aug. 1998.

[8] S. Geetha, k. K. S. Kumar, C.,R., K. Rao, M. Vijayan, D. C. Trivedi "EMI shielding: methods and material-A review", Journal of Applied Polymer Science, Wiley Interscience, 2009.

[9] P. Dehkhoda, A. Tavakoli, R. Moini, "An efficient and reliable shielding effectiveness of rectangular enclosure with numerous apertures", IEEE Transactions on Electromagnetic Compatibility, vol. 50, no. 1, pp. 208212, Feb 2008.

[10] N. J. L. Violette, D. R. J. White, M. F. Violette, Electromagnetic Compatibility, Springer ScienceBusiness Media, LLC, New York, 1987.

[11] C. C. Wang, C. Q. Zhu, X. Zhou, Z. F. Gu, "Calculation and analysis of shielding effectiveness of the rectangular enclosure with apertures", ACES Journal ,vol. 28, no. 6, pp. 535-545, Jun 2013.

[12] S. Dan, Y. Shen, Y. Gao, "3 High order mode transmission line model of enclosure with off-center aperture", in International Symposium on Electromagnetic Compatibility EMC 2007.

[13] "304/304L Stainless Steel Product Data Bulletin". Revision 04.25.13 Ak Steel Corporation , West Chester, Ohio, USA.

[14] Umran Ugur, "Resistivity of Steel". [Online]. Available : https://hypertextbook.com/ facts/2006/UmranUgur.shtml

[15] University of Hamburg HF-Radar home page "Power vs Voltage." [Online]. Available : http://wera.cen.unihamburg.de/DBM.shtml

[16] M. Alaydrus, Transmission Lines in Telecommunication, Graha Ilmu Press, Yogyakarta, 2009. 